\title{
RELATION OF TEMPERATURE CHANGES IN ASPHALT PAVEMENTS TO PAVEMENT BEARING CAPACITY EVALUATION
}

Temperature changes in asphalt pavements have to be taken into account at the diagnostic and evaluation process of pavements bearing capacity. Theoretical calculations resulting from general theory are not suitable for the practical use. Therefore the experimental test section with flexible and semi-rigid pavement was built and the temperatures were measured at different depths. The examples of typical temperature gradients for the hot summer and cold spring day are presented and their similarities are stated. The development of the simple method for the determination of mean temperature of pavement asphalt layers is described and the correction values relative to the temperature of pavement surface are shown for the time interval from $20^{00}$ to $8^{00}$ and the asphalt layers thickness of $210 \mathrm{~mm}$.

\section{Introduction}

Highways and roads as the important part of the traffic infrastructure must have sufficient structural performance to satisfy traffic requirements. Diagnostic and evaluation of bearing capacity of road pavements is one of the most important activities in evaluation procedures of road structural performance. In Slovakia the top layers of road pavements consist of asphalt. As stiffness of asphalt and consequently pavement response (measured deflections) changes according to temperature this parameter must be taken into account during the process of pavement bearing capacity evaluation. According to Slovak provisions [1] and [2] measured deflections or backcalculated moduli of asphalt layers have been "recalculated" to the "equivalent" temperature of $20^{\circ} \mathrm{C}$. Although different equations have been used the temperature of asphalts at the depth of $40 \mathrm{~mm}$ below the pavement surface is generally an input to the recalculation (it is assumed the temperature at this depth is mean temperature of asphalt layers). But in practice the temperature at the depth of $40 \mathrm{~mm}$ is usually measured only at the first testing point and it is considered as the representative mean temperature of asphalt layers for whole test section. As the pavement temperature changes along the test sections the differences in temperatures could be a cause of mistakes when the measured deflections are recalculated to the equivalent temperature. From this point of view the measurement of air and pavement surface temperature at each testing point seems as inevitable for the determination of right mean temperature of pavement asphalt layers.

\section{Theoretical background}

Different methods could be used for the pavement temperature calculation. Generally all methods are related to solar radiation, heat transfer and energy balance on the pavement surface. As stated at [3] the net rate of heat flow to and from a body $q_{\text {net }}$ can be calculated from the equation

$$
q_{\text {net }}=q_{s}+q_{a}+q_{t} \pm q_{c} \pm q_{k}-q_{r}
$$

where: $q_{s}$ - energy absorbed from direct solar radiation

$q_{a}$ - energy absorbed from diffuse radiation (scattered from the atmosphere)

$q_{t}$ - energy absorbed from terrestrial radiation (for the pavement can be considered to be 0 )

$q_{c}$ - energy transferred to or from the body as a result of convection

$q_{k}$ - energy transferred to or from the body as a result of conduction

$q_{r}$ - energy emitted from the body through outgoing radiation

Then, by writing each of the above flow rates in terms of temperatures the following equation for the calculation of the pavement surface temperature can be obtained

$$
\begin{aligned}
& 422 \alpha \tau_{\alpha}^{1 / \cos z} \cdot \cos z+\epsilon_{a} \sigma T_{a}^{4}-h_{c}\left(T_{s}-T_{a}\right)- \\
& -\frac{k}{d}\left(T_{s}-T_{d}\right)-\epsilon \sigma T_{s}^{4}=0
\end{aligned}
$$

where: $\alpha$ - surface absorptivity to the solar radiation

$\tau_{a}$ - transmission coefficient for unit air mass

$z$ - angle between the zenith and direction of the sun's rays

$\epsilon_{a}-0.49 \cdot\left(10^{-0,074 . \rho}\right)$

$\rho$ - vapour pressure varying between 1 and $10 \mathrm{~mm}$ of mercury

$\sigma$ - Stefan-Boltzman constant $=5.68 \cdot 10^{-8}\left[\mathrm{~W} \cdot \mathrm{m}^{-2} \cdot \mathrm{K}^{-4}\right]$

$T_{a}$ - air temperature $[\mathrm{K}]$

\footnotetext{
* Jozef Komačka, Martin Korenko, Jaroslav Piala

Department of Highway Engineering, Faculty of Civil Engineering, University of Žilina, Slovakia

E-mail: komacka@fstav.uniza.sk
} 
$T_{s}$ - surface temperature $[\mathrm{K}]$

$h_{c}$ - average convective heat transfer coefficient of surface $\left[\mathrm{W} \cdot \mathrm{m}^{-2} \cdot \mathrm{C}^{-1}\right.$ ]

$k$ - thermal conductivity [W.m ${ }^{-1} \cdot \mathrm{C}^{-1}$ ]

$d$ - depth below the surface $[\mathrm{m}]$

$T_{d}$ - temperature at depth $d[\mathrm{~K}]$

$\epsilon$ - emissivity

Thermal diffusion theory can be used for the calculation of temperature changes in the pavement structure. According to Fourier law the thermal diffusion and the changes of heat flow can be described by equations published in [4]

$$
\begin{aligned}
& q(x, t)=-\lambda \cdot \frac{\partial T(x, t)}{\partial x} \\
& \frac{\partial q(x, t)}{\partial x}=-\rho \cdot c \frac{\partial T(x, t)}{\partial t}
\end{aligned}
$$

The final equation resulting from the formulas (3) and (4) is then

$$
\frac{\partial T(x, t)}{\partial t}=\frac{\lambda}{\rho \cdot c} \cdot \frac{\partial^{2} T(x, t)}{\partial x^{2}}
$$

where: $q(x, t)$ - density of heat flow at the point $x$ and time $t$ [W.m $\mathrm{m}^{-2}$ ]

$\lambda \quad$ - thermal conductivity coefficient $\left[\mathrm{W} \cdot \mathrm{m}^{-1} \cdot \mathrm{K}^{-1}\right]$

$T(x, t)$ - temperature at the point $x$ and time $\mathrm{t}[\mathrm{K}]$

$\rho \quad$ - bulk density of the material $\left[\mathrm{kg} \cdot \mathrm{m}^{-3}\right]$

$c \quad$ - thermal capacity of the material $\left[\mathrm{J} \cdot \mathrm{kg}^{-1} \cdot \mathrm{K}^{-1}\right]$

Various computing method can be used to solve equation (5) but they are complicated in general and not very suitable for the practical applications. Therefore different empirical methods are used too and they differ according to their purpose. When pavement bearing capacity is tested, diagnostic equipment has usually the possibility to measure the air and pavement surface temperature at each testing point. The empirical method for the determination of mean temperature of pavement asphalt layers using these two temperatures has been developed at the Highway Engineering Department of the Civil Engineering Faculty.

\section{Experimental measurements}

The test section consists of flexible and semi-rigid pavement was built in Žilina (about $330 \mathrm{~m}$ above see level) to measure the temperature in pavement layers. The type and thicknesses of asphalt layers is given in table 1 . The temperature sensors were installed at different depths below the pavement surface (table 2) to measure

Asphalt layers of pavements

Table 1

\begin{tabular}{|c|l|}
\hline Semi-rigid pavement & Flexible pavement \\
\hline AC $11 \mathrm{~mm} 40 \mathrm{~mm}$ & AC $11 \mathrm{~mm} 40 \mathrm{~mm}$ \\
\hline AC $16 \mathrm{~mm} 90 \mathrm{~mm}$ & AC $16 \mathrm{~mm} 80 \mathrm{~mm}$ \\
\hline AC $22 \mathrm{~mm} 80 \mathrm{~mm}$ & AC $22 \mathrm{~mm} 100 \mathrm{~mm}$ \\
\hline
\end{tabular}

continually the temperature distribution in the pavement. Moreover the air temperature at $2 \mathrm{~m}$ above earth surface has been recorded automatically.

Positions of thermometers

Table 2

\begin{tabular}{|c|c|c|c|}
\hline \multicolumn{2}{|c|}{ Semi-rigid pavement } & \multicolumn{2}{c|}{ Flexible pavement } \\
\hline $\begin{array}{c}\text { Thermometer } \\
\text { number }\end{array}$ & $\begin{array}{c}\text { Depth below } \\
\text { the pavement } \\
\text { surface }\end{array}$ & $\begin{array}{c}\text { Thermometer } \\
\text { number }\end{array}$ & $\begin{array}{c}\text { Depth below } \\
\text { the pavement } \\
\text { surface }\end{array}$ \\
\hline $\mathrm{I} / 13$ & $5 \mathrm{~mm}$ & $\mathrm{II} / 13$ & $5 \mathrm{~mm}$ \\
\hline $\mathrm{I} / 12$ & $40 \mathrm{~mm}$ & $\mathrm{II} / 12$ & $40 \mathrm{~mm}$ \\
\hline $\mathrm{I} / 11$ & $130 \mathrm{~mm}$ & $\mathrm{II} / 11$ & $80 \mathrm{~mm}$ \\
\hline $\mathrm{I} / 10$ & $180 \mathrm{~mm}$ & $\mathrm{II} / 10$ & $120 \mathrm{~mm}$ \\
\hline $\mathrm{I} / 9$ & $210 \mathrm{~mm}$ & $\mathrm{II} / 9$ & $170 \mathrm{~mm}$ \\
\hline \multicolumn{2}{|c|}{} & $\mathrm{II} / 8$ & $220 \mathrm{~mm}$ \\
\hline
\end{tabular}

Results of measurements confirm the theoretical assumptions from equation (2). The temperature of pavement surface is related to the air temperature but do not depend only on this temperature (Fig. 1).

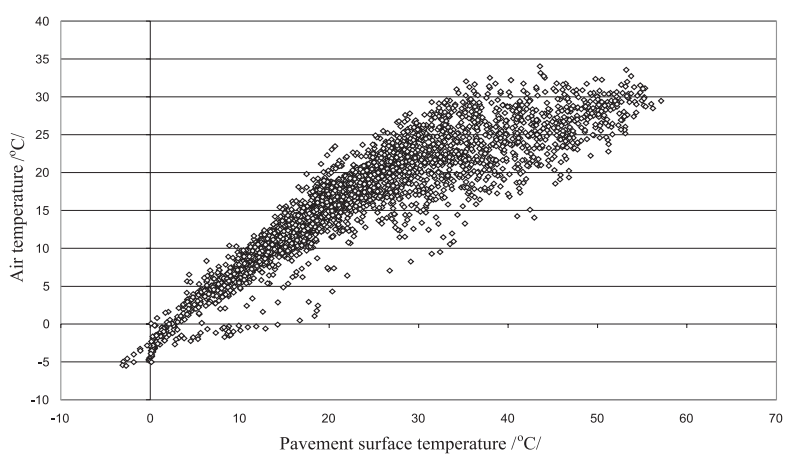

Fig. 1 Relationship between the temperature of air and pavement surface

Other outputs concern the temperature distribution in the pavement structure. It is evident the temperature at the different depths of pavement changes not only during long time period (month, year) but the changes occur within an individual day too and they are significant during hot summer days (Fig. 2). That means the temperature gradients at pavement layers change too and the mean temperature of asphalt layers varies at different hours of a day.

The temperature gradients at the different hours of cold spring and hot summer day are presented in Fig. 3. The similarities of gradients can be stated as:

- relatively small temperature change on the bottom of the lowest asphalt layer in comparison with the temperature changes on the pavement surface; 


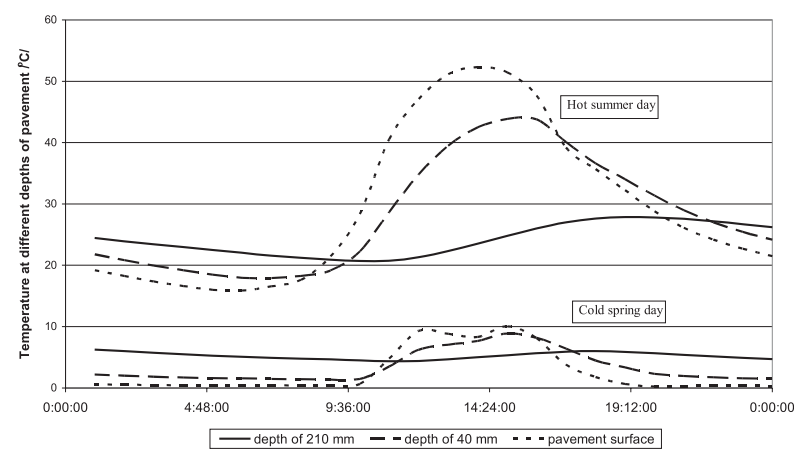

Fig. 2 Example of the temperature changes in the asphalt pavement layers

- steady temperature distribution in the asphalt layers and the approximately equal temperature gradient between the temperature at the top of pavement and at the bottom of the lowest asphalt layer; for the hot summer day it is from $23^{00}$ to $6^{00}$ and for the cold spring day from $20^{00}$ to $9^{00}$.

\section{Development of the empirical method}

For a consideration the experimental measurements the development of the empirical method for the determination of mean temperature of pavement asphalt layers using the air and pavement surface temperature was divided to two main stages regarding the time interval during a day. The first time interval is from $20^{00}$ to $8^{00}$ and the second from $8^{00}$ to $20^{00}$. The former is less compli- cated with the highest temperature at the bottom of the lowest asphalt layer and the lowest temperature at the top of pavement. The similar shape of the temperature gradients aside from the pavement and air temperature is other important fact.

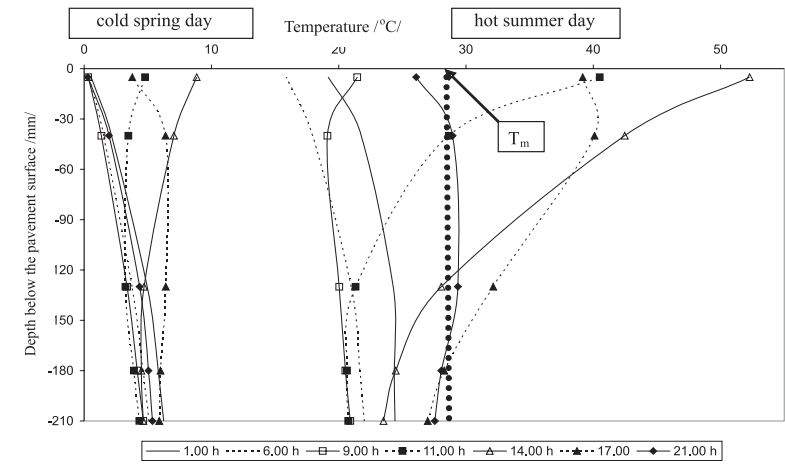

Fig. 3 Example of the temperature gradients in the asphalt layer

The mean temperature of asphalt layers $\left(T_{m}\right)$ was determined for each hour within the time interval from $20^{00}$ to $8^{00}$. As the mean temperature were considered the temperature where the areas between the temperature gradient line and the chosen vertical line (the area on right and left side from the chosen vertical line) were approximately equal (see Fig. 3 , thick dotted line, hot summer day, $21.00 \mathrm{~h}$ ). Then the difference between the pavement surface temperature and the mean asphalt layers temperature were determined. This procedure was carried out for the asphalt layers thickness of $130 \mathrm{~mm}$ and of $210 \mathrm{~mm}$ (to cover the most frequent

The correction values for the asphalt layers thickness of $210 \mathrm{~mm}$

Table 3

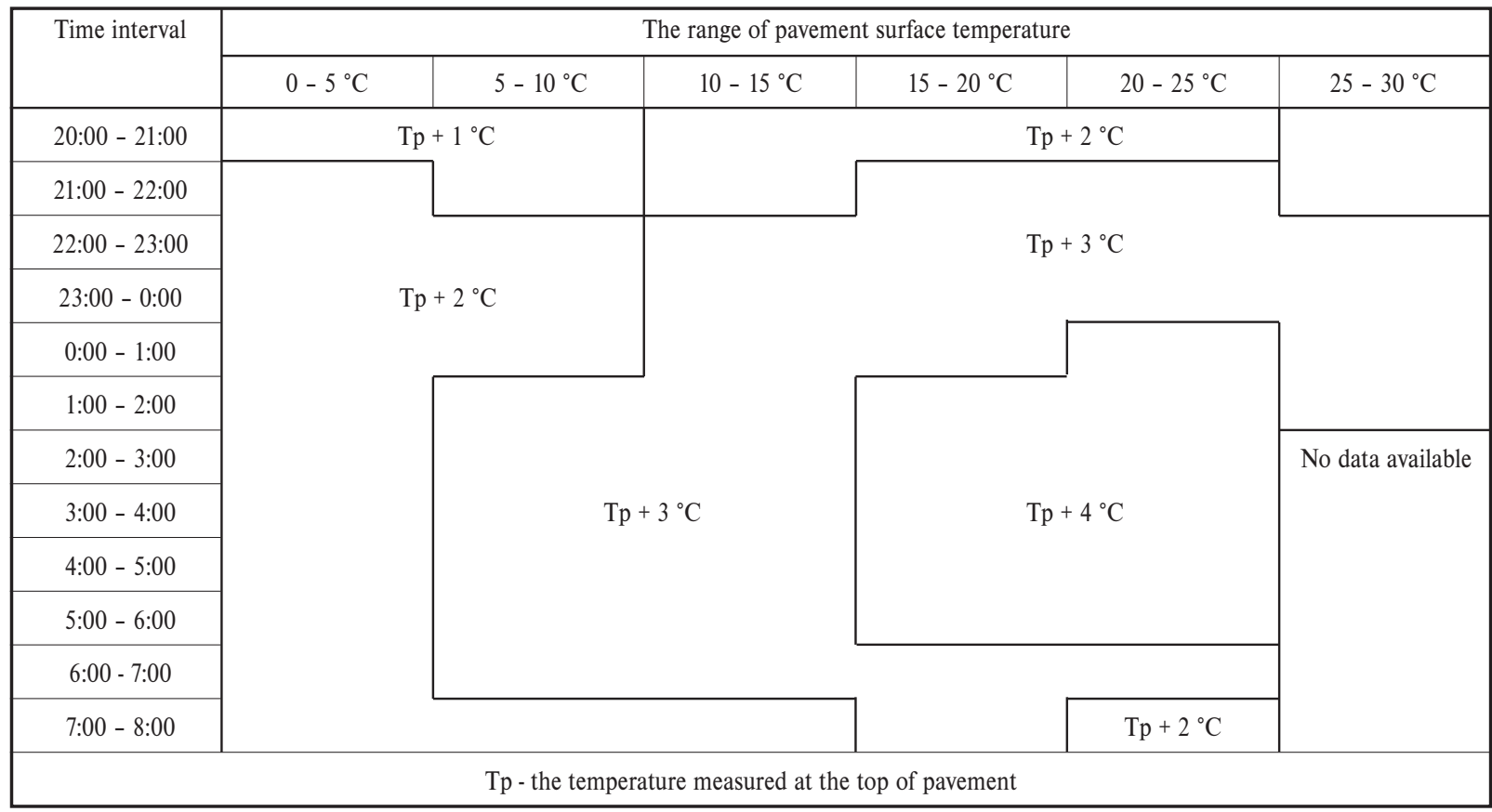


thickness of asphalt layers in pavements). All differences were processed according to the air temperature and the correction values were determined for the both asphalt layers thickness above (table 3). It is evident the pavement surface temperature is lower than the mean asphalt layer temperature and the difference varies according the time interval and the pavement surface temperature. At present the same procedure has been applied for the time interval from $8^{00}$ to $20^{00}$.

\section{Conclusions}

The temperature of asphalt layers influences their stiffness and response to loading. It is very important to take into account the temperature distribution in the asphalt pavement when pavement bearing capacity is evaluated and to determine the mean temperature of asphalt layers at the moment of diagnostics. The mean asphalt layers temperature depends on the pavement surface temperature, time interval within a day when measurement is carried out, asphalt layers thickness and weather tendency (heating, cooling and settled). The temperature gradients in the asphalt pavements are less complicated during the time interval from $20^{00}$ to $8^{00}$ with the highest temperature at the bottom of the lowest asphalt layer the lowest temperature at the top of pavement and the similar shape of the temperature gradients aside from the pavement and air temperature.

The analysis of experimental measurements showed that it is possible to determine the mean temperature of pavement asphalt layers during the time interval from $20^{00}$ to $8^{00}$. The simple method was developed for this purpose using the temperature of pavement surface measured at the moment of pavement bearing capacity diagnostics.

Acknowledgement: This work has been supported by the grant VEGA 1/3339/06 Influence of variability of deformation and thermal characteristics of asphalt layers to road pavement mechanics

\section{References}

[1] TP 01/2004 Repairs and reconstructions of pavement, Strengthening of asphalt pavements, Technical provisions, Ministry of Transport, Posts and Telecommunications SR, 2004

[2] TP 02/2006 Measurement and evaluation of asphalt pavements bearing capacity using FWD, Technical provisions, Ministry of Transport, Posts and Telecommunications SR, 2006

[3] SOLAIMANIAN, M., KENNEDY, T., W.: Predicting maximum pavement surface temperature using maximum air temperature and hourly solar radiation, Transportation Research Record 1417, pp. 1-11, TRB, National Research Council, Washington D.C., 1993

[4] ČOREJ, J., ČELKO, J., TROJANOVÁ, M.: Water and thermal regime of pavements and rail subgrade (in Slovak), Chap. 3.2.1, p. 43, VŠDS Žilina, 1994. 